\title{
On the Application of Computer Technology in College English Teaching
}

\author{
Wenxing Zhang \\ School of Humanities and Social Science \\ Jingdezhen Ceramic Institute \\ Jingdezhen, China \\ E-mail: vincent835712@163.com
}

\begin{abstract}
Corpus linguistics gains much development in China, and brings vigor and vitality to college English teaching reform. Compared with traditional English teaching modes, corpus has its unique advantages, and provides a greater room of learning and development for English learners. This paper studies the application of corpus in college English teaching and provides some suggestions for college English teaching.
\end{abstract}

Keywords- Corpus; English teachers; English teaching

\section{INTRODUCTION}

Currently, many universities are actively implementing the reform of college English teaching with some distinctive characteristics of times. From the traditional grammar-translation method to today's popular communicative approach, English educators have squeezed their minds and gained some favorable achievements. Scholars are actively exploring the outlet of reform, and have witnessed the tremendous changes in the field of language education. In the field of foreign language teaching and research, the rise of data-driven learning in the early 90 s of last century, the building of learner corpora at the turn of the century, and the sudden emergence of the comparative analysis of inter-language all serve a good indication of the trial and effort of the application of corpus technology and resources in foreign language teaching [1]. The rapid development and popularization of computer and its related technology pose a challenge for countless English teachers and enable them to build their own small or medium-size corpora for research and teaching. At present, many Chinese scholars have done some corpus-based language research [2]. In addition, from December 23 to 27 of 2009, Foreign Language Teaching and Research Press and National Research Center for Language Education Research held "Corpus Week", and organized "Senior Seminar for Corpora and Language Studies" and "The First National Symposium for Learner Corpus". Through such a series of activities, they hoped they could further promote the application of corpora in foreign language teaching and research, and enable more young teachers to learn and master corpus technology and properly use it in their English teaching.

\section{CORPORA AND CORPUS LINGUISTICS}

A corpus is a large electronic library of a certain capacity, using random sampling method according to some linguistic principles and collecting the continuity of naturally occurring language use in the form of text or speech fragments. The language information and data it provides are neither imaginary discourse nor few or individual cases which are simply excerpted from some books, but rather a purposeful and systematic collection of the oral and written discourse which are frequently used among the native speakers in their daily life, which enables the description of language to be based on the authentic language materials. So they can accurately reflect the linguistic phenomenon and have become indispensable basic resources for the theoretical and applied research of linguistics and language engineering. Modern corpus linguistics is a study of the large-scale corpus stored in a computer. The increasing development of computer science and technology and the gradual deepening of information bring some vigor to the growth of corpus linguistics; meanwhile the computer corpus linguistics has a significant impact on the study of language. Corpus constructed with the employment of computer technology enjoys several advantages, such as being large-scale, being multi-functional, and being easy retrieval, which no doubt has brought tremendous changes to the methods of linguistic research and a profound impact on the theoretical exploration of language. In the past two decades, corpus linguistics enjoyed considerable progress and influenced the disciplines related to language theoretically and methodologically. All kinds of corpora for different research purposes have been constructed and widely used in the following research areas: vocabulary, grammar, semantics, pragmatics, genre studies, social linguistics, oral studies, lexicography, language teaching and natural language processing, artificial intelligence, machine translation, speech recognition and synthesis, etc.

\section{CORPORA AND COLLEGE ENGLISH TEACHING REFORM}

Early in the 1960s to 1970 s, the period of the rise of corpus linguistics, pioneers of corpus linguistics and language educators in Europe, such as G. Leech, T. Johns, etc., regarded the application of corpus in language 
teaching as an important branch of corpus linguistics, because the two are a synthesis of mutual penetration [4].

The analysis of the characteristics of language and learner language using corpus can be applied to guide language teaching and improve classroom teaching. For example, the distribution and frequency of linguistic phenomena can help teachers to grasp the focus and difficulty of teaching, while the feedback of language using and errors of learners can help teachers diagnose some possible learning problems and devise some corresponding training. Corpus can also be used in teaching writing and syllabus design. Besides, corpus can also be used to teach material compiling and teach syllabus design and provide a scientific basis for the vocabulary, grammatical structures and their arrangement. Computer-assisted language learning with the help of corpus also is gaining much popularity. And the advantages of using corpus in English teaching are as follows:

1) Corpus only presents real language information and cases, which can create an authentic language environment for learners and better develop their English language proficiency. The examples in the existing English textbooks are made up by Chinese scholars solely for teaching purposes, some of which do not fit the real situation. The students are easily misled by these concocted cases and cannot make good progress.

2) Corpus enables students to understand their English level more clearly, find out the mistakes and promptly correct them. For foreign language learners, some usages they have already accepted are not correct, the reasons attributing to this are different, such as, the misinformation from the textbooks or teachers or the inadvertent used by themselves. The introduction of corpus can allow students to discover the problem timely and provide them with more authentic cases through concordance, which helps them to master the more native English.

3) Early introduced corpora could not be updated and changed due to the technical and financial constraints, while corpora developed since the 1990s can get their content updated regularly and the capacity expanded. The latest and most popular language usages can be timely assimilated to enrich the corpus, which allows learners to have access to the latest language materials and learn more practical knowledge of English. Therefore, English educators respond positively to the call of the Ministry of Education, vigorously carry out the research of self-study ability of English in the background of infomationization and internetization, and encourage students to use effective learning strategies to make full use of network, corpora and other resources assiduously to improve the their own comprehensive English ability.

4) The rich content of corpus provides learners with numerous learning materials, so students can have various choices and do not rigidly adhere to the teaching material with limited content. Total offer by keyword context, learners can easily get to know the text and context the words appear through keyword concordance. In addition, for some students of higher level, similar methods can be used to seek some academic literature of a given field and get some insights into the latest development of the academic orientation.

\section{THE APPLICATION OF CORPORA IN COLLEGE} ENGLISH TEACHING

The unique advantages of corpora enable them to be widely applied in many fields, such as bilingual comparative study, dictionary compilation, the compiling of grammar books and teaching references, the instruction and practice of translation. Corpora is also used in the classroom teaching of college English. Teachers can take advantage of corpora for the preparations of the class, selection of example sentences, and writing exercises and the questions. In this way, students can master various meanings of words or phrases, proceed to get familiar with the collocations, and can ultimately distinguish synonyms.

For the countless English learners in China, vocabulary learning is very important and extremely difficult, and most of them still memorize the new words mechanically. There has always been a misconception about new words study, that is, to master a new word is to know its pronunciation, spelling and meaning. It should be aware that in addition to this basic information, they must know the context and the sentence it may appear in. Only in this way can they truly grasp the usage of the word and freely use it. Fortunately, corpora can gradually eradiate this very misconception, because they can offer a large number of examples through concordance, which enables students to easily focus on various uses of a word and pay more attention to the context and sentence it may appear in.

The majority of users can make full use of corpora to learn and practice the usages of English phrases to skillfully apply phrases and collocations and ultimately use relatively native English. Collocations do not only include phrasal verbs, compound nouns, prepositional phrases, fixed phrases, idioms and other common terms used in conjunction structure, but also include numerous accepted matches. However, the collocations listed in any existing dictionary are limited, which cannot meet the higher demands of learners, while corpora can help students fill in the gaps in the recognition of phrases and sentence structure with more real-life examples to enhance the learning impression and achieve good learning effects. In addition, in the aspect of vocabulary discrimination, large-scale corpora providing a large number of collocations are better than traditional dictionaries.

The introduction and application of corpora in college English classroom are good news to the teachers, yet it also poses higher requirements and challenges to English teachers. Foreign Language Teaching and Research Press and National Research Center for Foreign Language Education have been organizing various forms of training of related corpus knowledge. Only teachers having a good mastery of the usages and functions of corpora can better teach the students. In addition, there is a strong correlation between the initiative and ability of applying foreign language materials and the effect of foreign language learning. Therefore, universities and teachers equipped with modern education concepts should provide students with foreign language learning materials as many as possible and encourage students to take the initiative to properly use the existing resources.

As an extension of the existing language teaching, corpus, after its introduction into foreign language 
classroom, allows students to directly contact with authentic language information of modern times and get fun and sense of achievement. Therefore, teachers need to update the traditional teaching mode and guide students to make full use of corpora resources to take the initiative to discover and understand language laws. The teachers can also organize classroom discussions. The role of teacher should also shift from the carrier of imparting knowledge to the guide and companion in the students' exploration of knowledge.

\section{CONCLUSIONS}

Corpus linguistics has got much development in China, and brought vigor and vitality to the reform of college English teaching. Compared with traditional English teaching mode, corpus has its unique advantages and provides a broad space for learning and a great room of development for English learners. Introducing corpus into English teaching can fundamentally change the understanding of the current foreign language teaching materials. In some well-equipped universities, teachers can directly use the online corpora, such as BNC, Cobuild and LDC, and their colorful language cases. The teachers can get familiar with a variety of linguistic phenomena through convenient search, sum up the language laws to solve the emerging teaching issues, and make corpora to better serve the modernization of classroom English teaching.

\section{ACKNOWLEDGMENT}

I would like to extend my thanks to my wife Zhang Wei who helped me a lot with the chores during the writing of the paper, and my colleague Mr. Xu Hong-yan who encouraged me a lot at the beginning of this writing.

\section{REFERENCES}

[1] Wei Nai-xing, Li Wen-zhong, and Pu Jian-zhong, The Applied Research of Corpora. Shanghai: Shanghai Foreign Language Education Press,2005.

[2] Yang Hui-zhong, An Introduction to Corpus Linguistics. Shanghai: Shanghai Foreign Language Education Press,2002.

[3] He An-ping, "On the Study of Corpora" in Journal of Foreign Languages, 1997(5), pp.21-26.

[4] He An-ping, Corpus Linguistics and English Teaching. Beijing: Foreign Language Teaching and Research Press, 2004. 